\title{
Commentary: Setting the standard for robotic pulmonary resection
}

\section{Katherine D. Gray, MD, and Matthew J. Bott, MD}

Anatomic pulmonary resections are performed using a robotic platform with increasing frequency but have an approximate learning curve of 20 to 40 cases even for surgeons with previous video-assisted thoracoscopic surgery experience. ${ }^{1}$ Currently, high-quality, peer-to-peer instructional resources are scarce despite the growing acceptance of this technique. Although many video atlases of thoracic procedures exist, few are professionally produced and edited by experts in the field with the amount of attention to detail included in this manuscript. This manuscript and accompanying video entitled "Robotic-Assisted Left Lower Pulmonary Lobectomy: Eleven Steps" by Dr Servais aims to establish a framework for instruction in robotic lung resections. $^{2}$

Dr Servais should be commended for his thorough technical description of a standard left lower lobectomy. This operative manual is unique in the attention applied to specific details of the procedure, such as setup and port placement, which are frequently overlooked in similar instructional videos. These will hopefully allow for surgeons and institutions with less robotic experience to avoid some of the common pitfalls that are typically only learned in surgery through trial and error. Safety issues such as the ready availability of pledgeted sutures and sponge sticks are also important to note. In addition to robotic technique, this video reinforces the ability to adhere to standard oncologic principles such as complete

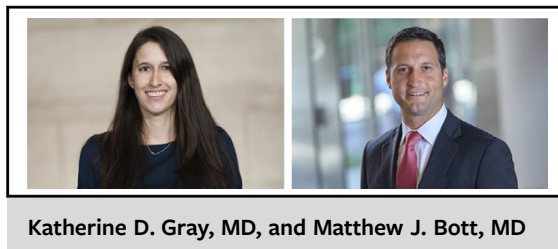

CENTRAL MESSAGE

Developing an instructional

framework for robotic pulmonary resections.

hilar dissection and systematic mediastinal lymph node dissection using a robotic minimally invasive approach. An interesting point that may become relevant to a wider audience is that the author is a left-handed surgeon. Although the author does indicate that the robotic platform allows for a degree of ambidexterity, adoption of the technique may require adaptation for right-hand dominant surgeons.

We believe that this video manuscript is a wellconstructed instructional video that will be a valuable resource to trainees and surgeons who are learning robotic resections, as well as institutions aiming to develop a robotic practice.

\section{References}

1. Power AD, D'Souza DM, Moffatt-Bruce SD, Merritt RE, Kneuertz PJ. Defining the learning curve of robotic thoracic surgery: what does it take? Surg Endosc. 2019;33:3880-8.

2. Servais EL. Robotic-assisted left lower-lobe pulmonary lobectomy: eleven steps. J Thorac Cardiovasc Surg Tech. 2021;10:473-9.
From the Department of Thoracic Surgery, Memorial Sloan Kettering Cancer Center, New York, NY.

Disclosures: Dr Bott reports consulting fees from AstraZeneca and Intuitive Surgical. Dr Gray reported no conflicts of interest.

The Journal policy requires editors and reviewers to disclose conflicts of interest and to decline handling or reviewing manuscripts for which they may have a conflict of interest. The editors and reviewers of this article have no conflicts of interest.

Received for publication Aug 2, 2021; revisions received Aug 2, 2021; accepted for publication Aug 2, 2021; available ahead of print Aug 6, 2021.

Address for reprints: Matthew J. Bott, MD, Department of Thoracic Surgery, Memorial Sloan Kettering Cancer Center, 1275 York Ave, New York, NY (E-mail: bottm@mskcc.org).

JTCVS Techniques 2021;10:480

2666-2507

Copyright (c) 2021 The Authors. Published by Elsevier Inc. on behalf of The American Association for Thoracic Surgery. This is an open access article under the CC BY-NCND license (http://creativecommons.org/licenses/by-nc-nd/4.0/).

https://doi.org/10.1016/j.xjtc.2021.08.008 